KONSTANTIN I. POPOV ${ }^{1,2 *}$, PREDRAG M. ŽIVKOVIĆ ${ }^{1}$, NEBOJŠA D. NIKOLIĆ

${ }^{1}$ University of Belgrade, Faculty of Technology and Metallurgy, Belgrade, Serbia, ${ }^{2}$ University of Belgrade, ICTM-Institute of Electrochemistry, Belgrade, Serbia
Review paper

ISSN 0351-9465, E-ISSN 2466-2585

UDC:620.197.1

doi:10.5937/ZasMat1601055P

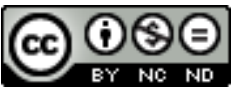

Zastita Materijala 57 (1)

$55-62$ (2016)

\title{
Electrochemical aspects of formation of dendrites
}

\begin{abstract}
The one of the main contributions of Belgrade Electrochemical School to the field of metal electrodeposition is investigation of a mechanism of formation and growth of the disperse deposits. Spongy-like, cauliflower-like, needle-like, carrot-like, dendrites of various shapes, etc. are the typical disperse forms obtained by the electrodeposition processes. From the electrochemical point of view, a dendrite, as the most significant disperse form, is defined as an electrode surface protrusion that grow under activation or mixed control, while deposition to the flat part of the electrode surface is under complete diffusion control. In this paper, all electrochemical aspects concerning mechanism of formation and growth of dendrites are reviewed.
\end{abstract}

Keywords: Electrodeposition, dendrite, copper, cadmium, mechanism.

\section{PREFACE}

In the Chapter 1 of Modern Electrochemistry [1] in consideration of a state of excitement, Despic and Popov are situated with twelve most important electrochemists by the sentence "..... Despic and Popov wrote an article that described electroforming of almost anything from ions in solution: powder or dendrites, whiskers or pyramids ...". Besides, in the foreword of Fundamental Aspects of Electrometallurgy [2], Bockris wrote "The contents of the present volume illustrate how certain fields of science become settled in certain countries. Industrial organic chemistry grew up in Germany, and developed predominantly there until World War II. In electrometallurgy, the intellectual development has been largely in Serbia ...." . Obviously, the contribution of Belgrade Electrochemical School (BES) to the field of metal electrodeposition is important, especially to the morphology of electrodeposits. Among numerous publications produced by BES there are two books $[2,3]$, twelve chapters in edition Modern Aspects of Electrochemistry [3 - 15], and one chapter in the book Electroanalytical Chemistry Research Trends [16].

\footnotetext{
${ }^{*}$ Corresponding author: Konstantin I. Popov

E-mail: nnikolic@ihtm.bg.ac.rs

Paper received: 22. 10. 2015.

Paper accepted: 15. 12. 2015.

Paper is available on the website:

www.idk.org.rs/casopis
}

In these publications all aspects of morphology of electrodeposited metal are discussed, from dendritic growth initiation and dendritic growth [2, 3, $11]$ to the bright deposits formation $[2,3,8]$ and the effect of hydrogen co-deposition on morphology of electrodeposits [3, 9, 14]. One of the most important conclusion derived by BES is the mechanism of disperse deposits formation, based on different behaviour of the macroelectrodes and microelectrodes under the same conditions of electrodeposition. The aim of this article is to discuss this phenomenon in the way given in [11] for the growth of dendrites.

\section{THE STATEMENT OF THE PROBLEM}

\subsection{Macroelectrodes and microelectrodes}

The most frequently used form of the cathodic polarization curve equation for flat or large spherical electrode of massive metal is given by

$$
j=\frac{j_{0}\left(f_{\mathrm{c}}-f_{\mathrm{a}}\right)}{1+\frac{j_{0} f_{\mathrm{c}}}{j_{\mathrm{L}}}}
$$

where $j, j_{0}$ and $j \mathrm{~L}$ are the current density, exchange current density and limiting diffusion current density, respectively, and

$$
\begin{aligned}
& f_{\mathrm{c}}=10^{\frac{\eta}{b_{\mathrm{c}}}} \\
& f_{\mathrm{a}}=10^{-\frac{\eta}{b_{\mathrm{a}}}}
\end{aligned}
$$


where $b_{\mathrm{c}}$ and $b_{\mathrm{a}}$ are the cathodic and anodic Tafel slopes and $\eta$ is the overpotential. Equation (2.1) is modified for use in electrodeposition of metals by taking cathodic current density and overpotential as positive. Derivation of Eq. (2.1) is performed under assumption that the concentration dependence of $j_{0}$ can be neglected $[2,10,17]$.

It is known [17] that electrochemical processes on microelectrodes in bulk solution can be under activation control at overpotentials which correspond to the limiting diffusion current density plateau of the macroelectrode. The cathodic limiting diffusion current density, $j_{L, s p}$ for steadystate spherical diffusion is given by:

$$
j_{\mathrm{L}, \mathrm{sp}}=\frac{n F D C_{0}}{r}
$$

and for steady-state linear diffusion, $j\llcorner$ by:

$$
j_{\mathrm{L}}=\frac{n F D C_{0}}{\delta}
$$

where $n$ is the number of transferred electrons, $F$ is the Faraday constant, $D$ and $C_{0}$ are the diffusion coefficient and bulk concentration of the depositing ion, respectively, $r$ is the radius of the spherical microelectrode and $\delta$ is the diffusion layer thickness of the macroelectrode. It follows from Eqs. (2.4) and (2.5) that:

$$
\frac{j_{\mathrm{L}, \mathrm{sp}}}{j_{\mathrm{L}}}=\frac{\delta}{r}
$$

An electrode around which the hydrodynamic diffusion layer can be established, being considerably lower than dimensions of it, could be considered as a macroelectrode. An electrode, mainly spherical, whose diffusion layer is equal to the radius of it, satisfying

$$
\delta>r
$$

can be considered as a microelectrode [18].

According to Eq. (2.1) for

$$
f_{c} \gg f_{a} \text { and } \frac{j_{0} f_{c}}{j_{L}}>1
$$

the cathodic process on the macroelectrode enters full diffusion control, i.e.,

$$
j \cong j_{L}
$$

Simultaneously, the cathodic current density on the spherical microelectrode, $j_{\mathrm{sp}}$, is given by:

$$
j_{\mathrm{sp}}=\frac{j_{0}\left(f_{\mathrm{c}}-f_{\mathrm{a}}\right)}{1+\frac{j_{0} f_{\mathrm{c}}}{j_{\mathrm{Lsp}}}}
$$

or, because of Eq. (2.6)

$$
j_{\mathrm{sp}}=\frac{j_{0}\left(f_{\mathrm{c}}-f_{\mathrm{a}}\right)}{1+\frac{j_{0}}{j_{\mathrm{L}}} \cdot \frac{r}{\delta} \cdot f_{\mathrm{c}}}
$$

and, if condition (2.8) is also valid, but

$$
\frac{r}{\delta} \rightarrow 0
$$

Eq. (2.11) can be rewritten in the form

$$
j=j_{0} f_{c}
$$

This means that the process on the microelectrode in the bulk solution can be under complete activation control at the same overpotential at which the same process on the macroelectrode is simultaneously under full diffusion control*.

The different behavior of macroelectrodes and microelectrodes under the same conditions of electrodeposition causes the disperse deposits formation.

\subsection{Active microelectrodes placed inside the diffusion layer of the active macroelectrode}

Naturally, the microelectrodes can be placed on the macroelectrodes inside their diffusion layers. Let us consider the model of surface irregularities shown in Fig. 1. The electrode surface irregularities are buried deep in the diffusion layer, which is characterized by a steady linear diffusion to the flat portion of the surface $[7,10,19]$.

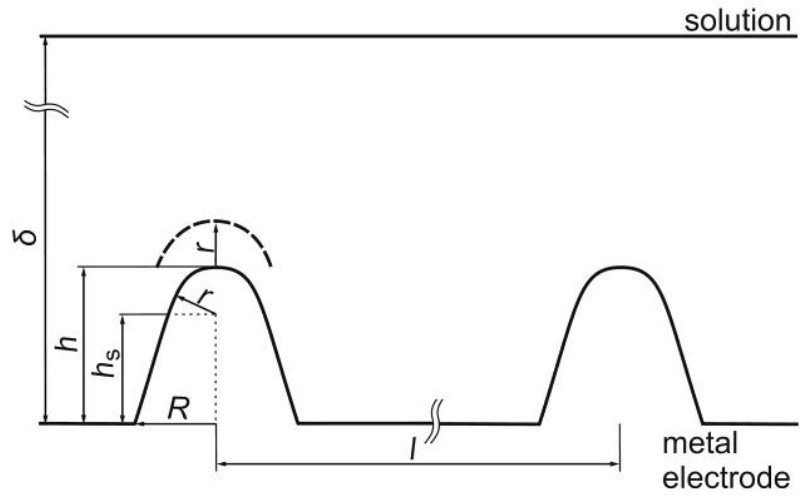

Figure 1 - Model of a paraboloidal surface protrusion; $h$ is the height of the protrusion relative to the flat portion of the surface, $h_{s}$ is the corresponding local side elongation, $r$ is the radius of the protrusion tip, $R$ is the radius of the protrusion base, $\delta$ is the thickness of the diffusion layer, $\delta>>h$ and $I>>R$, where $I$ is the distances between two protrusions.

\footnotetext{
* The reversible potential of a surface with radius of curvature $r_{\text {cur }}$ would depart from that of a planar surface by the quantity $\Delta E_{\mathrm{r}}=2 \sigma \mathrm{V} /\left(n F r_{\text {cur }}\right)$, where $\sigma$ is the interfacial energy between metal and solution, and $V$ molar volume of metal [18]. It is valid at extremely low $r_{\text {cur }}$, being of the order of few millivolts, and it can be neglected except in some special cases, like the stability of the shape of the tips of dendrites [18].
} 
At the side of an irregularity, the limiting diffusion current density, $j_{L, S}$, is given as:

$$
j_{\mathrm{L}, \mathrm{S}}=\frac{n F D C_{0}}{\delta-h_{\mathrm{s}}}=j_{\llcorner} \frac{\delta}{\delta-h_{\mathrm{s}}}
$$

Obviously, this is valid if the protrusion height does not affect the outer limit of the diffusion layer, and that a possible lateral diffusion flux supplying the reacting ions can be neglected. At the tip of an irregularity, the lateral flux cannot be neglected and the situation can be approximated by assuming a spherical diffusion current density, $j_{L, \text { tip }}$, given by [7]:

$$
j_{L, \text { tip }}=\frac{n F D C^{*}}{r}
$$

where $C^{*}$ is the concentration of the diffusing species at a distance $r$ from the tip, assuming that around the tip a spherical diffusion layer having a thickness equal to the radius of the protrusion tip is formed [18]. Obviously, if $R>\delta$ the spherical diffusion layer around the tips of protrusion cannot be formed and Eq. (2.16) is valid:

$$
j_{L, \text { tip }}=\frac{n F D C_{0}}{\delta-h}
$$

If deposition to the macroelectrode is under full diffusion control, the distribution of the concentration $C$ inside the linear diffusion layer is given by [17]:

$$
C=C_{0} \frac{h}{\delta}
$$

where $0 \leq h \leq \delta$. Hence,

$$
C^{\star}=C_{0} \frac{h+r}{\delta}
$$

and

$$
j_{L, \text { tip }}=j_{L}\left(1+\frac{h}{r}\right)
$$

because of Eqs. (2.5), (2.15) and (2.18).

The tip radius of the paraboloidal protrusion is given by $[17,18,20]$

$$
r=\frac{R^{2}}{2 h}
$$

and substitution of $r$ from Eq. (2.20) in Eq. (2.19) gives

$$
j_{\mathrm{L}, \mathrm{tip}}=j_{\mathrm{L}}\left(1+\frac{2 h^{2}}{R^{2}}\right)
$$

or

$$
j_{L, \text { tip }}=j_{L}\left(1+2 k^{2}\right)
$$

where

$$
k=\frac{h}{R}
$$

If $h=R, k=1$, hence for a hemispherical protrusion,

$$
\begin{aligned}
& j_{\mathrm{L}, \mathrm{tip}}=3 j_{\mathrm{L}} \\
& \text { if } h \ll R, k \rightarrow 0, \\
& j_{\mathrm{L}, \mathrm{tip}} \rightarrow j_{\mathrm{L}}
\end{aligned}
$$

and if $R<h, k \rightarrow \infty$ and

$$
\dot{j}_{\mathrm{L}, \mathrm{tip}} \rightarrow \infty
$$

Substituting of $j_{L, \text { tip }}$ from Eq. (2.22) instead of $j L$ in Eq. (2.1) and further rearranging gives:

$$
j_{\text {tip }}=\frac{j_{0, \text { tip }}\left(f_{\mathrm{c}}-f_{\mathrm{a}}\right)}{1+\frac{j_{0, \text { tip }}}{j_{\mathrm{L}}} \cdot \frac{1}{1+2 k^{2}} f_{\mathrm{c}}}
$$

if $j_{0}$ around the tip is $j_{0, \text { tip }}$ and if the surface energy term $[17,18]$ can be neglected. The current density on the tip of a protrusion, $j_{\text {tip }}$, is determined by $k$, hence by the shape of the protrusion. If $k \rightarrow 0, j_{\text {tip }} \rightarrow$ $j$ (see Eq. (2.1)) and if $k \rightarrow \infty, j_{\text {tip }} \rightarrow j_{0, \text { tip }}\left(f_{\mathrm{c}}-f_{\mathrm{a}}\right)>>j$. The electrochemical process on the tip of a sharp needle-like protrusion can be under pure activation control outside the diffusion layer of the macroelectrode. Inside it, the process on the tip of a protrusion is under mixed control, regardless it is under complete diffusion control on the flat part of the electrode for $k \rightarrow 0$. If $k=1$, hence for hemispherical protrusion, $j_{\text {tip }}$ will be somewhat larger than $j$, but the kind of control will not be changed. It is important to note that the current density to the tip of hemispherical protrusion does not depend on the size of it if $k=1$. This makes a substantial difference between spherical microelectrodes in bulk solution [11] and microelectrodes inside diffusion layer of the macroelectrode [17]. In the first case the limiting diffusion current density depends strongly on the radius of the microelectrode.

\subsection{The essence of dendritic deposits formation}

The characteristics of dendritic growth are:

a. there is a certain well-defined critical overpotential value below which dendrites do not grow,

b. dendrites exhibit a highly ordered structure and grow and branch in well-defined directions. According to Wranglen [21], a dendrite is a skeleton of a monocrystal and consists of a stalk and branches, thereby resembling a tree.

It is known that dendritic growth occurs selectively at three types of growth sites [4]: 
I. dendritic growth occurs at screw dislocations. Sword-like dendrites with pyramidal tips are formed by this process [4, 17].

II. many investigations of the crystallographic properties of dendrites have reported the existence of twin structures [22-24]. In the twinning process, a so-called indestructible reentrant groove is formed. Repeated onedimensional nucleation in the groove is sufficient to provide for growth extending in the direction defined by the bisector of the angle between the twin plants [4].

III. it is a particular feature of a hexagonal closepacked lattice that growth along a high-index axis does not lead to the formation of low index planes. Grooves containing planes are perpetuated, and so is the chance for extended growth by the one-dimensional nucleation mechanism [25].

In all the above cases, the adatoms are incorporated into the lattice by repeated onedimensional nucleation. On the other hand, deposition to the tip of screw dislocations can be theoretically considered as deposition to a point; in the other two cases, the deposition is to a line.

From the electrochemical point of view, a dendrite can be defined as an electrode surface protrusion that grows under activation or mixed control, while deposition to the flat part of the electrode surface is under complete diffusion control [2, 17, 20].

Considering the model of surface irregularities shown in Fig. 1, the surface irregularities are buried deep in the diffusion layer, which is characterized by a steady linear diffusion to the flat portion of completely active surface.

If the protrusion does not affect the outer limit of the diffusion layer, i.e., if $\delta>h$, the limiting diffusion current density to the tip of the protrusion from Fig. $1, j_{L, \text { tip }}$, is given by

$$
\dot{J}_{\mathrm{L}, \mathrm{tip}}=j_{\mathrm{L}}\left(1+\frac{h}{r}\right)
$$

Substitution of $j_{L, \text { tip }}$ from Eq. (2.19) into Eq. (2.1) produces for $h / r>>1$ :

$$
j_{\text {tip }}=j_{0, \text { tip }}\left(f_{\mathrm{c}}-f_{\mathrm{a}}\right)
$$

where $j_{0, \text { tip }}$ is the exchange current density at the tip of a protrusion.

Obviously, deposition to the tip of such protrusion inside the diffusion layer is activationcontrolled relative to the surrounding electrolyte, but it is under mixed activation-diffusion control relative to the bulk solution.

If deposition to the flat part of electrode is a diffusion controlled process and assuming a linear concentration distribution inside diffusion layer, the concentration $C_{\text {tip }}$ at the tip of a protrusion can be given by modified Eq. (2.17) [17].

$$
C_{\text {tip }}=C_{0} \frac{h}{\delta}
$$

According to Newman [26] the exchange current density at the tip of a protrusion is given by

$$
j_{0, \text { tip }}=j_{0}\left(\frac{C_{\text {tip }}}{\mathrm{C}_{0}}\right)^{\xi}
$$

Where

$$
\xi=\frac{\mathrm{d} \log j_{0}}{\mathrm{~d} \log C_{0}}
$$

and $j_{0}$ is the exchange current density for a surface concentration $C_{0}$ equal to that in the bulk,

or

$$
j_{0, \text { tip }}=j_{0}\left(\frac{h}{\delta}\right)^{\xi}
$$

because of Eq. (2.17a).

Taking into account Eq. (2.28), the current density to the tip of a protrusion is then given by:

$$
j_{\text {tip }}=j_{0}\left(\frac{h}{\delta}\right)^{\xi}\left(f_{\mathrm{c}}-f_{\mathrm{a}}\right)
$$

being under mixed control due to the $(h / \delta)^{\xi}$ term, which takes into account the concentration dependence of $j_{0, \text { tip }}$, expressing in this way a mixed controlled electrodeposition process.

Outside the diffusion layer $h \geq \delta$, and Eq. (2.32) becomes:

$$
j_{\text {tip }}=j_{0}\left(f_{\mathrm{c}}-f_{\mathrm{a}}\right)
$$

indicating pure activation control, as the $(h / \delta)^{\xi}$ term is absent.

For the dendrite growth, the current density to the tip of a protrusion formed on the flat part of the electrode surface growing inside the diffusion layer should be larger than the corresponding limiting diffusion current density [27]. Hence,

$$
j<j_{\text {tip }}
$$

the protrusion grows as a dendrite.

In accordance with Eq. (2.34), instantaneous dendrite growth is possible at overpotentials larger than some critical value, $\eta_{\mathrm{c}}$, which can be derived from Eq. (2.32) as shown in [2, 7]

$$
\eta_{\mathrm{c}}=\frac{b_{\mathrm{c}}}{2.3} \ln \frac{j_{\mathrm{L}}}{j_{0}}\left(\frac{\delta}{h}\right)^{\xi}
$$

and minimum overpotential at which dendritic growth is still possible, $\eta_{\mathrm{i}}$, is given by 


$$
\eta_{\mathrm{i}}=\frac{b_{\mathrm{C}}}{2.3} \ln \frac{j_{\mathrm{L}}}{j_{0}}
$$

for $f_{\mathrm{c}} \gg f_{\mathrm{a}}$, where $h$ and $\delta$ are the protrusion height and the diffusion layer thickness, respectively. For very fast processes, when $j_{0} / j \mathrm{~L}>1$, and if $f_{\mathrm{c}} \approx f_{\mathrm{a}}$ but $f_{\mathrm{c}}>f_{\mathrm{a}}$, Eq. (2.35) becomes:

$$
\eta_{\mathrm{c}}=\frac{R T}{n F} \frac{j_{\mathrm{L}}}{j_{0}}\left(\frac{\delta}{h}\right)^{\xi}
$$

and Eq. (2.36)

$$
\eta_{\mathrm{i}}=\frac{R T}{n F} \frac{j_{\mathrm{L}}}{j_{0}}
$$

meaning that in the case of Ohmic controlled reactions, dendritic growth can be expected at very low overpotentials, or better to say, if $j_{0} \rightarrow \infty$, instantaneous dendritic growth is possible at all overpotentials if only mass transfer limitations are taken into consideration.

In fact, dendrite propagation under such conditions is under diffusion and surface energy control and $\eta_{\mathrm{c}}$ is then given by $[18,27]$ :

$$
\eta_{\mathrm{c}}=\frac{8 \sigma \mathrm{V}}{n F h}
$$

where $\sigma$ is the interfacial energy between metal and solution and $V$ is the molar volume of the metal, and minimum overpotential at which dendritic growth is still possible, $\eta_{\mathrm{i}}$ is given by:

$$
\eta_{\mathrm{i}}=\frac{8 \sigma \mathrm{V}}{n F \delta}
$$

Hence, a critical overpotential for initiation dendritic growth is also expected in such cases, being of the order of few millivolts [2, 7, 27].

\subsection{Determination of $\eta_{i}$ and $\eta_{c}$}

The dendritic growth starts at overpotentials larger than the one which corresponds to the beginning of the limiting diffusion current density plateau $[2,7]$.

There is an induction period before the initiation of dendritic growth [18]. During this induction period, dendrite precursors are formed and become sufficiently high to satisfy Eq. (2.35) at a given overpotential.

The initiation of dendritic growth is followed by a change in the slope of the current density-time curves [2, 4, 7], indicating a change in the growth mechanism of the deposit.

The slopes of these dependences are similar to each other and independent of the deposition overpotential during the non-dendritic amplification of the surface-coarsening [2].
The change of the slope of the current-time dependences due to the dendritic growth initiation will be treated here in somewhat simplified way.

The limiting diffusion current density to the elevated points of a surface protrusion, $j_{\mathrm{L}, \mathrm{e}}$, is given by:

$$
j_{\mathrm{L}, \mathrm{e}}=\frac{n F D C_{0}}{\delta-h}
$$

and

$$
j_{\llcorner}=\frac{n F D C_{0}}{\delta}
$$

to the flat part of the electrode.

The limiting diffusion current density will then be given by

$$
j_{\mathrm{L}}=\theta \frac{n F D C_{0}}{\delta}+\frac{1-\theta}{\mathrm{N}} \sum_{i=1}^{i=\mathrm{N}} \frac{n F D C_{0}}{\delta-h_{\mathrm{i}}}
$$

where $\theta$ is the flat part of electrode surface and $N$ is the number of elevated points on the electrode surface, and $h_{\mathrm{i}}$ changes with time according to Eq. (2.44):

$$
h_{\mathrm{i}}=h_{0, \mathrm{i}} \exp \left(\frac{V D C_{0}}{\delta^{2}} t\right)
$$

which describes nondendritic surface coarseness amplification.

It is obvious that $\frac{\mathrm{d} j}{\mathrm{~d} t}$ does not depend on overpotential.

After initiation of dendritic growth, the slopes become dependent on the overpotential. A dendrite is a surface protrusion growing under mixed or activation control, while deposition to the flat part of the electrode surface is under complete diffusion control. The overpotential $\eta$ and current density $j_{\text {tip }}$ on the tip of a dendrite are related by:

$$
j_{\text {tip }}=j_{0} \frac{h}{\delta} f_{\mathrm{c}}
$$

for $f_{\mathrm{c}} \gg f_{\mathrm{a}}$ and Eq. (2.43) can be rewritten in the form

$$
j=j_{\mathrm{L}} \theta+(1-\theta) j_{0} \frac{f_{\mathrm{C}}}{\mathrm{N}} \sum_{i=1}^{i=\mathrm{N}} \frac{h_{\mathrm{i}}}{\delta}
$$

and $\frac{\mathrm{d} j}{\mathrm{~d} t}$ in this case depends on overpotential.

Hence, the maximum overpotential at which the slope of the apparent current density-time dependence remains constant and equal to that in non-dendritic amplification of the surfaceroughness corresponds to $\eta_{i}$. The minimum overpotential at which this slope cannot be recorded corresponds to $\eta_{\mathrm{c}}$. 
In this way $\eta_{\mathrm{i}}$ and $\eta_{\mathrm{c}}$ can be estimated. It is known that the $j-t$ dependences are different from case to case owing to different mechanisms of dendritic growth initiation and dendritic growth [2]. As a result of this, the analytical approach to the determination of $\eta_{\mathrm{i}}$ and $\eta_{\mathrm{c}}$ must be specific for each system under consideration; the procedure for one particular case is as follows.

Typical log (current)-time dependences obtained for copper deposition from 0.20 $\mathrm{M} \mathrm{CuSO}_{4}$ in $0.50 \mathrm{M} \mathrm{H}_{2} \mathrm{SO}_{4}$ at overpotentials belonging to the limiting diffusion current plateau are shown in Fig. 2. According to the above discussion, it is clear that the intersection points of the two linear dependencies determines the induction time of dendritic growth initiation [27].

The induction times for dendritic growth initiation extracted from the graphs in Fig. 2 can be presented as a function of overpotential, and the critical overpotential for instantaneous dendritic growth can be obtained by extrapolation to zero induction time.

The critical overpotential of dendritic growth initiation can be determined by plotting the logarithm of the slopes of the straight lines from Fig. 2 as a function of overpotential and the intersection point of the two straight lines determines $\eta_{\mathrm{i}}$. A similar procedure was followed for the deposition of cadmium from $0.10 \mathrm{M} \mathrm{CdSO}_{4}$ in $0.50 \mathrm{M} \mathrm{H}_{2} \mathrm{SO}_{4}$.

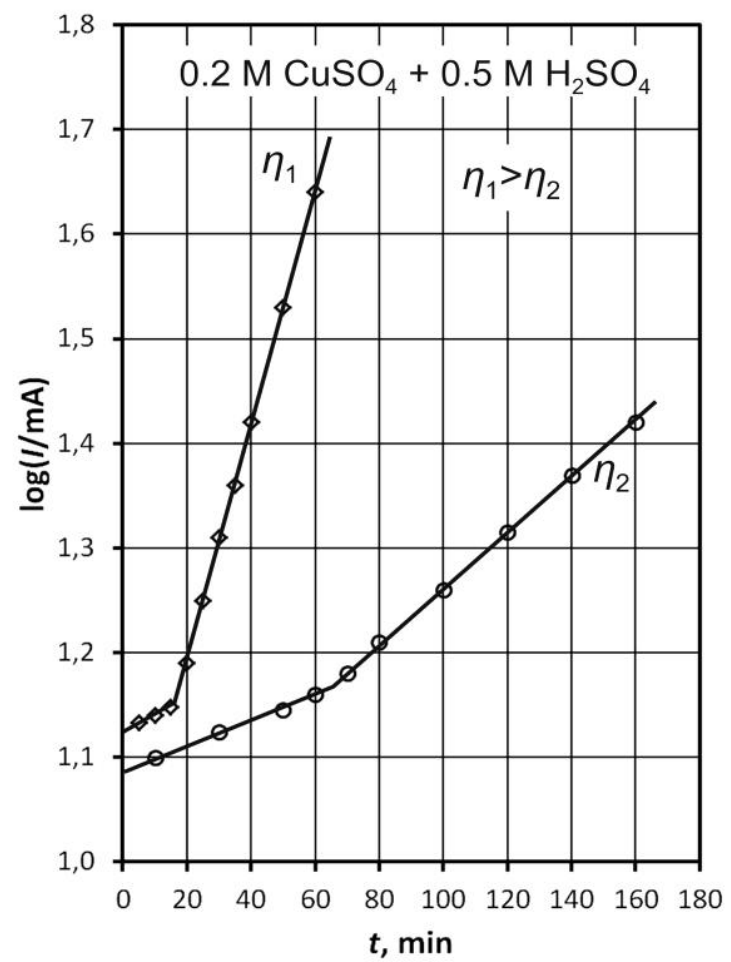

Figure 2 - log I as a function of time for copper deposition. (According to [11]).

The $\eta_{\mathrm{i}}$ and $\eta_{\mathrm{c}}$ of $260 \mathrm{mV}$ and $660 \mathrm{mV}$ for copper deposition (lower $j_{0}$ value) and $27 \mathrm{mV}$ and $110 \mathrm{mV}$ for cadmium deposition (larger $j_{0}$ value), are successfully determined using the above given procedure.

The schematic presentation of cross sections of the copper and cadmium deposits obtained at $\eta<\eta_{\mathrm{i}}, \eta_{\mathrm{i}}<\eta<\eta_{\mathrm{c}}$, and $\eta>\eta_{\mathrm{c}}$ are schematically presented in Figs. 3 and 4 , respectively. It can be seen that there is no dendrite formation when $\eta<$ $\eta_{\mathrm{i}}$, both compact and dendritic deposits are formed when $\eta_{\mathrm{i}}<\eta<\eta_{\mathrm{c}}$ and only dendritic metal is deposited when $\eta>\eta_{\mathrm{c}}$. This is in perfect agreement with findings of Calusaru [28] for the morphology of deposits of the same metals deposited at overpotentials corresponding to full diffusion control.

a)

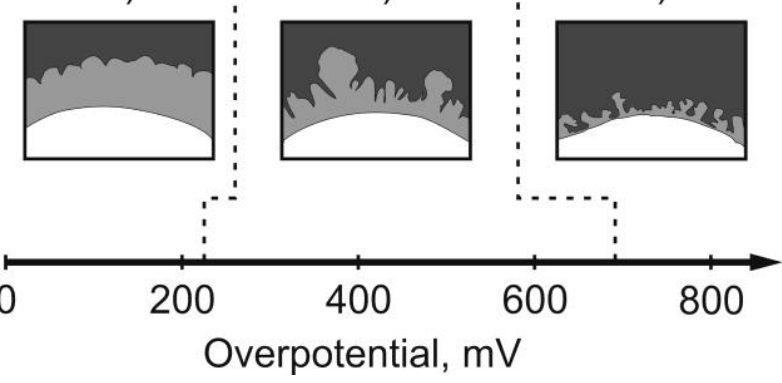

Figure 3 - Schematic presentation of copper deposits obtained by the potentiostatic deposition of copper from $0.20 \mathrm{M} \mathrm{CuSO}_{4}$ in $0.50 \mathrm{M} \mathrm{H}_{2} \mathrm{SO}_{4}$ on copper wire electrodes previously plated with nickel: a) overpotential: $200 \mathrm{mV}$, deposition time: 6 hours; b) overpotential: $300 \mathrm{mV}$, deposition time: 5 hours, and c) overpotential: $700 \mathrm{mV}$, deposition time: 2 min. a)

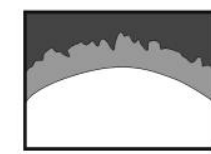

0 b)

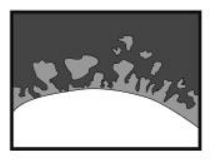

60 c)

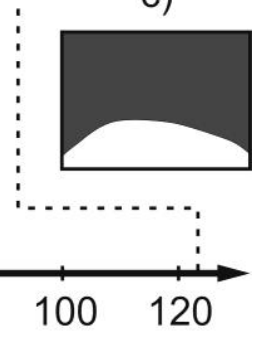

Overpotential, $\mathrm{mV}$

Figure 4 - Schematic presentation of cadmium deposits obtained by the potentiostatic deposition of cadmium from $0.10 \mathrm{M} \mathrm{CdSO}_{4}$ in $0.50 \mathrm{M} \mathrm{H}_{2} \mathrm{SO}_{4}$ on copper wire electrode: a) overpotential: $20 \mathrm{mV}$, deposition time: 8 hours; b) overpotential: $40 \mathrm{mV}$, deposition time: 2 hours, and c) overpotential: 120 $\mathrm{mV}$, deposition time: $9 \mathrm{~min}$.

It is known [6] that, apart from decreasing the concentration of the depositing ion, the formation of a dendritic deposit can also be enhanced by 
increasing the concentration of the supporting electrolyte, increasing the viscosity of the solution, decreasing the temperature, and decreasing the velocity of motion of the solution. Practically, all the above facts can be explained by Eqs. (2.36) and (2.38), assuming that a decrease in $\eta_{\mathrm{i}}$ means enhanced dendrite formation because of the lower electrical work required to produce the dendrites. The possibility of obtaining dendrites of $\mathrm{Pb}$ [29] and Sn [30] from aqueous solutions at lower overpotentials than required for the formation of dendrites of $\mathrm{Ag}$ from aqueous solutions can also be explained by Eq. (2.40) owing to the much lower melting points of these metals, i.e., their lower surface energy at room temperature. Dendrites of silver can be obtained from molten salts at overpotentials of a few millivolts [18], as in the case of $\mathrm{Pb}$ and $\mathrm{Sn}$ deposition from aqueous solutions $[29,30]$, because the difference between the melting point of silver and the working temperature for deposition from molten salts is not very different from the difference between the melting point of lead or tin and room temperature. On the other hand, dendrites grow from screw dislocation and nuclei of higher indices or twinned ones only [2, 4, 7]. The probability of formation of such nuclei increases with increasing overpotential [31] and $\eta_{\text {, }}$, can also be defined as the overpotential at which they are formed. Regardless of this, Eqs. (2.36), (2.38) and (2.40) illustrate well the effect of different parameters on the initiation of dendritic growth.

It is obvious that the electrochemical conditions, as well as the crystallographic ones, under which dendritic deposits are formed can be precisely determined. One problem that still seems to remain unsolved is the question what causes the dendrite precursors to appear at regularly spaced locations along the dendrite stem. Further investigations in this direction are necessary.

\section{Acknowledgement}

This paper was supported by the Ministry of Education, Science and Technological Development of the Republic of Serbia under the research project: "Electrochemical synthesis and characterization of nanostructured functional materials for application in new technologies" (Project No. 172046).

\section{REFERENCES}

[1] J.O`M.Bockris, A.K.N.Reddy (1998) GamboaAldeco M.: Modern Electrochemistry 1, Ionics, Kluwer Academic/Plenum Publishers, New York, p. 2.

[2] K.I.Popov, S.Djokić, B.N.Grgur (2002) Fundamental aspects of electrometallurgy, Kluwer Academic/ Plenum Publishers, New York, p. 1-305.
[3] K.I.Popov, S.Djokić, N.D.Nikolić, V.D.Jović (2016) Morphology of Electrochemically and Chemically Deposited Metals, Springer, New York.

[4] A.Despić, K.I.Popov (1972) Transport controlled deposition and dissolution of metals, In: Conway B.E., Bockris J.O'M. (Eds), Modern Aspects of Electrochemistry, vol. 7. Plenum Press, p. 199-313.

[5] K.I.Popov, M.Maksimović (1989) Theory of the Effect of Electrodeposition at Periodically Changing Rate on the Morphology of Metal Deposition, In: Bockris J.O'M. and Conway B.E. (Eds), Modern Aspects of Electrochemistry, vol. 19, Plenum Press, p. 193-250.

[6] K.I.Popov, M.G.Pavlović (1993) Electrodeposition of Metal Powders with Controlled Grain Size and Morphology, In: White R.W., Bockris J.O'M. and Conway B.E. (Eds), Modern Aspects of Electrochemistry, vol. 24, Plenum Press, p. 299 391.

[7] K.I.Popov, N.Krstajić, M.Čekerevac (1996) The mechanism of formation of coarse and disperse electrodeposits, In: White R.E., Conway B.E., Bockris J.O'M. (Eds), Modern Aspects of Electrochemistry, vol. 30, Plenum Press, p. 261312.

[8] N.D.Nikolić, Z.Rakočević, K.I.Popov (2005) Nanostructural Analysis of Bright Metal Surfaces in Relation to their Reflectivities, In: Conway B.E., Vayenas C.G., White R.E. and Gamboa-Adelco M.e. (Eds), Modern Aspects of Electrochemistry, vol. 38, Kluwer Academic/Plenum Publishers, p. 425-474.

[9] N.D.Nikolić, K.I.Popov (2010) Hydrogen Codeposition Effects on the Structure of Electrodeposited Copper, In: Djokić S.S. (Ed), Electrodeposition: Theory and Practice, Series: Modern Aspects of Electrochemistry, vol. 48, Springer, p. 1-70.

[10] K.I.Popov, P.M.Živković, N.D.Nikolić (2010) The Effect of Morphology of Activated Electrodes on their Electrochemical Activity, In: Djokić S.S. (Ed), Electrodeposition: Theory and Practice, Series: Modern Aspects of Electrochemistry, vol. 48, Springer, p. 163-213.

[11] K.I.Popov, N.D.Nikolić (2012) General Theory of Disperse Metal Electrodeposits Formation, In: Djokić S.S. (Ed), Electrochemical Production of Metal Powders, Series: Modern Aspects of Electrochemistry, vol. 54, Springer, p. 1-62.

[12] V.D.Jović, N.D.Nikolić, U.Č.Lačnjevac, B.M.Jović, K.I.Popov (2012) Morphology of Different Electrodeposited Pure Metal Powders, In: Djokić S.S. (Ed), Electrochemical Production of Metal Powders, Series: Modern Aspects of Electrochemistry, vol. 54, Springer, p. 63-123.

[13] N.D.Nikolić, K.I.Popov (2012) Electrodeposition of Copper Powders and Their Properties, In: Djokić S.S. (Ed), Electrochemical Production of Metal Powders, Series: Modern Aspects of Electrochemistry, vol. 54, Springer, p. 125-185. 
[14] N.D.Nikolić (2012) Porous Copper Electrodes Formed by the Constant and the Periodically Changing Regimes of Electrolysis, In: Djokić S.S. (Ed), Electrochemical Production of Metal Powders, Series: Modern Aspects of Electrochemistry, vol. 54, Springer, p. 187-249.

[15] N.D.Nikolić, K.I.Popov (2014) A New Approach to the Understanding of the Mechanism of Lead Electrodeposition, In: Djokić S.S. (Ed), Electrodeposition and Surface Finishing, Series: Modern Aspects of Electrochemistry, vol. 57, Springer, p. 85-132.

[16] N.D.Nikolić, S.B.Krstić, Lj.J.Pavlović, M.G.Pavlović, K.I.Popov (2009) The mutual relation of decisive characteristics of electrolytic copper powder and effect of deposition conditions on them, In: Hayashi K. (Ed), Electroanalytical Chemistry Research Trends, NOVA Publishers, p. 185-209.

[17] J.W.Diggle, A.Despić, J.O'M.Bockris (1969) The mechanism of the dendritic electrocrystallization of zinc, J Electrochem Soc, 116, 1503-1514.

[18] J.Barton, J.O'M.Bockris (1962) The electrolytic growth of dendrites from ionic solutions, Proc Roy Soc A268, 485-505.

[19] K.I.Popov, P.M.Živković, B.N.Grgur (2007) Physical and mathematical models of an inert macroelectrode modified with active hemispherical microelectrodes, Electrochim Acta, 52, 4696-4707.

[20] A.Despić, J.Diggle, J.O`M.Bockris (1968) Mechanism of formation of zinc dendrites, $J$ Electrochem Soc, 115, 507-508.

[21] G.Wranglen (1960) Dendrites and growth layers in the electrocrystallization of metals, Electrochim Acta, 2,130-146.
[22] C.Bechtoldt, F.Ogburn, J.Smith (1968) Structure and morphology of electrodeposited molybdenum dendrites, J Electrochem Soc, 115, 813-816.

[23] J.W.Faust, H.John (1963) Growth twins in F.C.C metals, J. Electrochem Soc, 110, 463-464.

[24] J.W.Faust, H.John (1961) Germanium dendritic studies. I. Studies of thin structures and the seeding mechanism, J Electrochem Soc, 108, 855-860.

[25] I.N.Justinijanović, A.Despić (1973) Some observation on the properties of zinc electrodeposited from alkaline zincate solutions, Electrochim Acta, 18, 709-712.

[26] J.S.Newman (1973) Electrochemical Systems, Prentice-Hall, Inc. Engelwood Cliffs, N. J.

[27] K.I.Popov, M.D.Maksimović, J.Trnjavčev, M.G.Pavlović (1981) Dendritic electrocrystallization and the mechanism of powder formation in the potentiostatic electrodeposition of metals, J Appl Electrochem, 11, 239-246.

[28] A.Calusaru (1979) Electrodepositon of Metal Powders, Material Science Monography, vol III, Elsevier, Amsterdam.

[29] K.I.Popov, N.V.Krstajić, R.M.Pantelić, S.R.Popov (1985) Dendritic electrocrystalisation of lead from lead nitrate solution, Surf Technol, 26, 177-183.

[30] K.I.Popov, M.G.Pavlović, J.N.Jovićević (1989) Morphology of Tin powder particles obtained in electrodeposition on copper cathode by constant and square - wave pulsating overpotential from $\mathrm{Sn}(\mathrm{II})$ alkaline solution, Hydrometallurgy, 23, 127137.

[31] N.A.Pangarov (1967) Twining processes in the electrocrystallization of face-centred cubic metals, Phys Stat Sol, 20, 371-377.

\section{IZVOD}

\section{ELEKTROHEMIJSKI ASPEKTI FORMIRANJA DENDRITA}

Jedan od glavnih doprinosa Beogradske elektrohemijske škole u polju elektrohemijskog taloženja metala je istraživanje mehanizma formiranja i rasta disperznih taloga. Sunđerasti, karfiolasti, nalik iglama i šargarepi, dendriti različitog oblika, itd. su tipične disperzne forme dobijene procesima elektrohemijskog taloženja metala. Sa elektrohemijske tačke gledišta, dendrit, kao najznačajnija disperzna forma, je definisan kao izbočina na elektrodnoj površini koja raste pod aktivacionom ili mešovitom kontrolom, dok je taloženje na ravnom delu elektrodne površine pod punom difuzionom kontrolom. U ovom radu prikazani su svi elektrohemijski aspekti koji se odnose na mehanizam formiranja i rasta dendrita.

Ključne reči: Elektrohemijsko taloženje, dendrit, bakar, kadmijum, mehanizam.

Pregledni rad

Rad primljen: 22.10.2015.

Rad prihvaćen: 15.12 .2015$.

Rad je dostupan na sajtu: www.idk.org.rs/casopis 